\title{
Analysis on the Residential Space Characteristics of Nantou Ancient City in Shenzhen Under Spontaneous Construction
}

\author{
Zhaoxin Hu \\ School of Urban Planning and Design, Peking University Shenzhen Graduate School, Shenzhen, China
}

\section{Email address:}

18126352670@163.com

\section{To cite this article:}

Zhaoxin Hu. Analysis on the Residential Space Characteristics of Nantou Ancient City in Shenzhen Under Spontaneous Construction. Science Innovation. Vol. 7, No. 3, 2019, pp. 95-101. doi: 10.11648/j.si.20190703.13

Received: July 8, 2019; Accepted: August 26, 2019; Published: August 27, 2019

\begin{abstract}
Nantou ancient city is one of the typical urban villages in shenzhen. Different from the traditional top-down planning, most of its buildings are built by residents spontaneously. Such construction logic creates unique spatial morphological characteristics. Starting from the behavior of the villagers spontaneously built, combined with the existing landscape features, and Understanding the spatial features from the fixation line, the competition of space, and the diversity of the morphological characteristics. typological method is adopted to extract the form characteristics of plane and elevation, to further understand the formation mechanism of its specific features and spatial logic, to help to provide reference for the reconstruction of urban villages based on micro-renewal.
\end{abstract}

Keywords: Urban Village, Spontaneous Construction, Style and Features, Spatial Morphology, Typology, Nantou Ancient City

\section{自发建造下的深圳南头古城居住空间形态特征探析}

\section{胡兆昕}

北京大学深圳研究生院城市规划与设计学院, 深圳, 中国

\section{邮箱}

18126352670@163.com

摘要: 南头古城是深圳市典型的城中村之一, 与自上而下的传统规划不同, 其大部分建筑是由居民自发建造而成, 这 样的建造逻辑造就了独特的空间形态特征。从村民自发建造的行为出发, 与现有风貌特征相结合, 从空间发展的中的 固结线、空间博亦和最终所呈现的形态多样性三方面把握其空间建造特征, 同时采用类型学方法提取其平面与立面的 形式特征进行解读, 进一步理解其特定风貌的生成机制与空间逻辑, 为当下以微更新为主的城中村改造提供借鉴。

关键词: 城中村, 自发建造, 风貌, 空间形态, 类型学, 南头古城

\section{1. 引言}

不同的历史时段, 自组织与他组织程度各有侧重, 但总的来说, 自组织的力贯穿整个城市史发展各时段。
许多场所是在没有设计师的情况下形成的, 或者有些城 市虽然曾经经过设计, 但却在日常生活秩序中悄然改变。 自组织系统是开放的, 不断地与外部环境之间进行物质、 能量、信息的交流, 不断运动变化。[1]其演化的动力是 
一定秩序下自组织主体之间的的竞争和协同, 并最终呈 现出特定的风貌。

南头古城是深圳典型的城中村之一。城中村是中国 市场经济时期的快速城市化与城乡二元结构相碰撞的矛 盾产物, 作为一种自发形成并相对独立的“村落”, 在城 市剧烈发展的扩张的边缘, 成为城市与偏远地区的介质。 原住民的身份随城市化进程不断更迭, 从失地农民到自 建房主，再到房东。在矛盾运动的外界条件下，村民以 自组织的形式对宅基地及村内共有空间进行逐步建设, 最终呈现出一个丰富的空间样本。[2]“自发性”是促使城 中村特有空间形态生成的根本动力, 是小场所内的文化 与场所空间的契合, 城中村空间形态最终呈现出在一定 秩序下自发建造所产生的空间博亦与自洽性, 最终形成 其复杂多元的空间形态与建筑风貌。本文对类型分析与 处理借鉴阿尔甘（G.C.Argan）的观点, 按照等级: (1) 街 区的尺度与建筑组织: 建筑群、街道空间、城市形态; (2)建筑尺度与大的组合元素：建筑室内外空间、院落空 间、建筑类型等; (3)细部比例: 屋顶形式、开间、进深、 门、窗、入口、阳台等, 以自发建造过程为出发点再审 视古城空间形态。[3]

\section{2. 自发建造下的空间生长机制}

每户村民在村组织划分的固定建筑基底下进行空间 营造，古村空间的成为村民在城市中的利益争夺对象， 空间博亦贯穿始终。[4]但空间的生长不是无序生长, 村 落基地和建筑基底都被历史、规划所形成的固结线所限 制。城中村村民的空间生长是在一定限制下的空间争夺 与博弯。

\section{1. 自发建造下的空间固结线}

借鉴欧洲地理学城市形态研究的基本理论方法,通过 对南头古城系统形成过程的分析,发现"固结线的不同表现 形式, 即古城墙、外部市政道路, 中山公园等对古城形 态形成的深层制约。[5]

\subsection{1. 村落基地固结线}

城内主要道路除县署前街(今中山东街和中山西街)为 东西向外, 是古代的营国思想的缩影。自明万历元年立 新安县之后, 建成“九街”格局。而今, “九街”的完整古 格局已经不复存在, 南头古城城内只保留了“六纵一横” 的空间格局。[6]

在原有农田被征收之后，政府对失地农民划拨了宅 基地和工商用地。1999年3月深圳出台《市人大常委会关 于坚决查处违法建筑的决定》掀起城中村抢建高潮，到 2004 年 《深圳市城中村改造暂行规定》 这五年是深圳 特区城中村发展的高潮阶段。[7]南头古城的民居大量抢 建在 90 年代到 00 年初。村民跟随市场需求的变化不断重 建或加建, 从而陆续建成以居住为主的城中村为主导的 风貌。

东大门、南大门与城墙的围合, 北面与中山公园毗 邻（其中包括南头古城的北城墙）, 西侧为南头中学。
中山公园始建与 1925 年, 西侧南头中学由凤岗学校发展 而来, 于1995年建设新校区。古城墙与地标性公共建筑 成为南头古城的固结线（图1）。使城内高密度、高容积 率下的土地利用状况下, 并没有无限制的向外部蔓延, 而是基本保留了清代遗留的城池整格局。

\subsection{2. 宅基地的固结线}

宅基地是由村民原有祖宅的基底划定，因历史格局 延续了不规则的街道与建筑边界。建筑的基底与建筑之 间形成不规则的空地。道路呈现出不规则的平面形制 (图2)。在宅基地划分时期, 隐形的固结线发挥作用, 使原有格局得到保留。在之后的城中村生长过程中, 居 民对于公共用地不加干涉。与邻里之间的博亦中，村民 个体较少随意占用公共用地, 多通过协商共同侵占公共 领域, 且多通过出挑占有道路上空。固结线对于南头古 城的控制作用是其无序生长的前提。

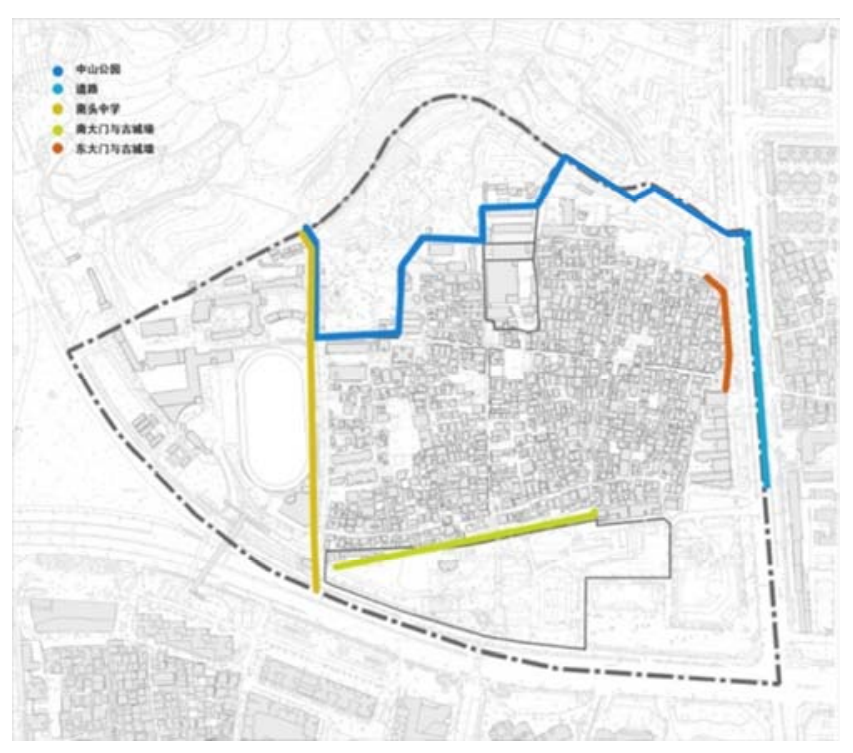

图1 南头古城的固结线。

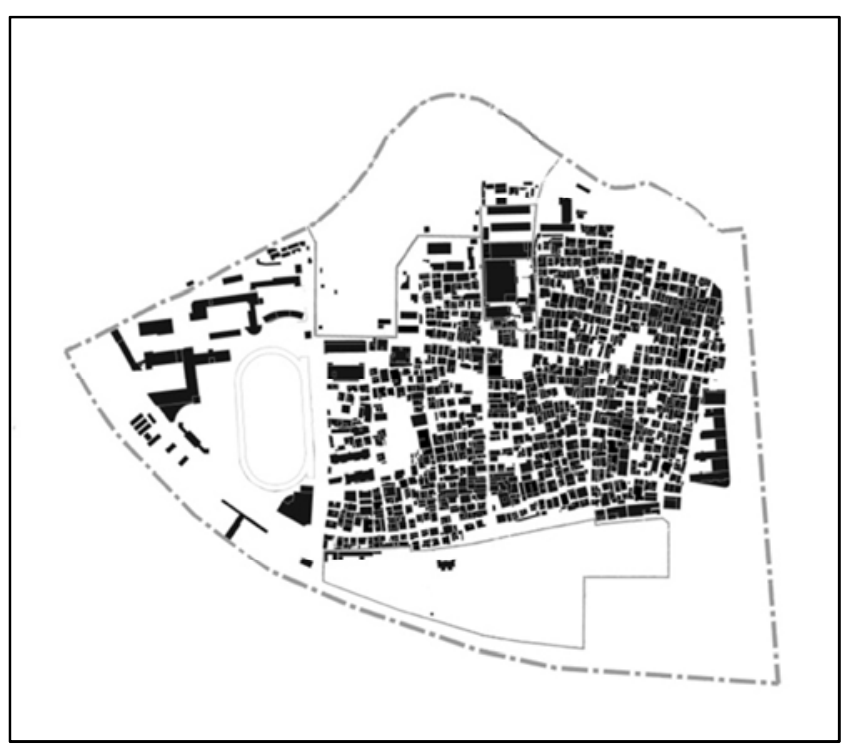

图2 不规则街道与建筑边界。 


\section{2. 自发建造下的空间博弃}

村民群体自建房与政府规章制度之间的博峦，在邻 里之间进行空间争夺与协商。在坚直方向的建筑高度和 出挑、基地占用三个维度（图3）体现。[8]

旧时的村落结构以宅基地产权延承的方式得以保留, 城中村由此出现大量不规则的街道公共空间。在二层以 上, 村民会通过出挑的方式进行空间占领, 且通常在相 互协商的基础上。城中村自建房利用建筑的出挑来获得 公共空间占有的最大化。利用悬臂梁, 使连续梁、板、 伸出基地红线范围外。两侧近乎相同的出挑距离, 是建 造中空间博亦的均衡。在地面则利用出挑产生的灰空间, 沿墙摆放桌椅、停放自行车等, 作为对公共空间的占有 [8]南头古城的民居经历了由留有庭院的祖宅到拆除围墙, 尽量占满宅基地, 继而上空出挑占用公共空间的变化过 程（图4）。

在建筑高度上的追逐主要是因为经济利润以及邻里 的空间博亦。最初的功能是居住, 一家一地的农村宅基 地政策决定基底面积是有限的, 为满足后代居住需求, 只有不断在高度上开始加建设。到 90 年代后期, 发展租
赁经济已经成为最主要的加建动力, 村民尽可能在高度 上扩充空间。

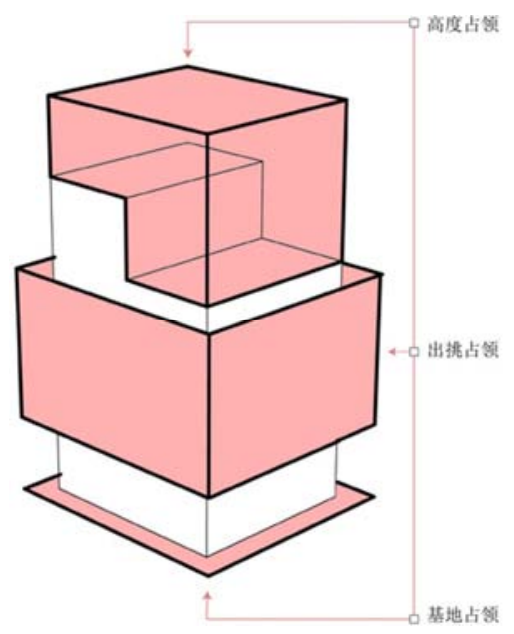

图3 空间博亦。

来源: 许志强, 广州大学建筑与城规学院教师. 城中村自建房研究——建造与博亦.

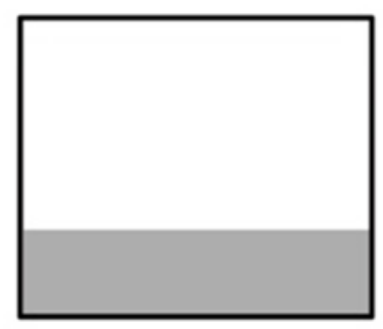

原庭院空间

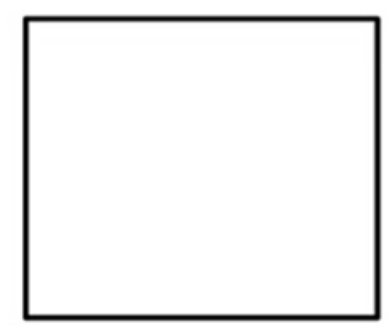

挤占痤院

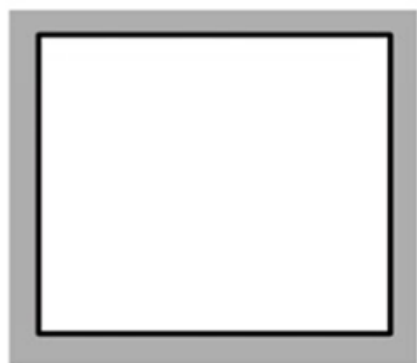

出挑占用外部街道上空空间

图4 庭院空间改造过程。

\section{3. 自发建造下的空间形态多样性}

在固结线的束缚作用下，居民与上层制度之间，居 民与居民之间的空间竞争不断发生, 最终呈现出城中村 丰富多元的风貌特征。区别于统一的规划和管理, 城中 村建筑形态十分丰富, 具有随机性与有机的协同性, 其 建筑形式各部相同, 但相互协调。采用意大利类型学派 的理论与方法, 对农民自建房的平面、立面及各层次细 部进行类型提取, 并试图分析特定社会、经济、文化对 建筑特征的影响。

\section{1. 平面类型提取}

通过随机采样（图5）, 入户走访调查, 对城中村农 民自建房的平面形制做类型上的提取。走访根据户数 (1-6户) 、楼梯位置分为 12 种情况, 得出简化还原后的 结构图式（图6）。

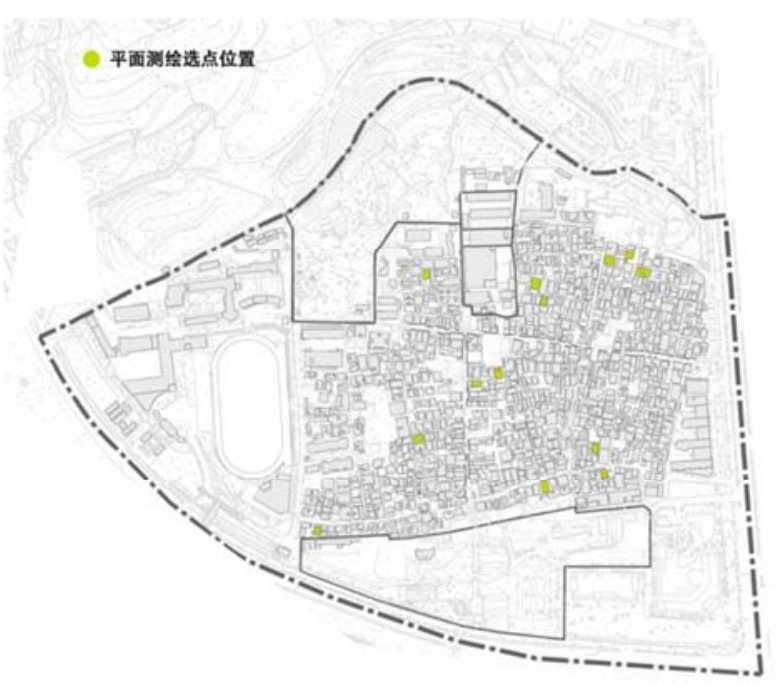

图5 采样选点位置。 

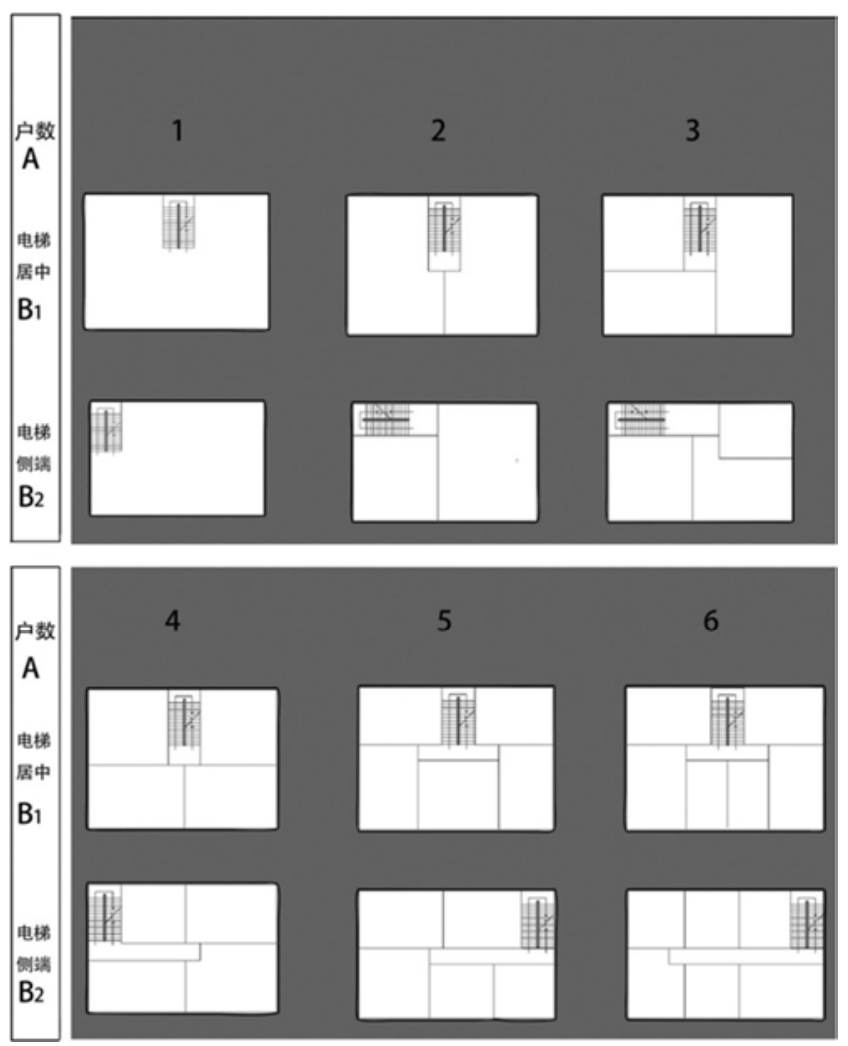

图6 平面类型的提取。

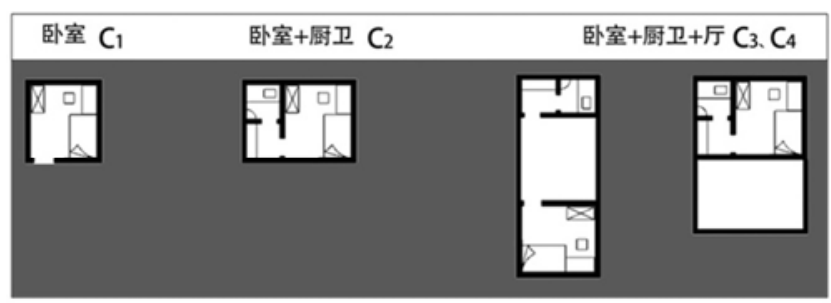

图7 每户内部空间组合形式类型。

以实用主义的功能、空间利用率出发的简单组合, 是 村民自建中朴素价值观的空间表达。

\section{2. 立面类型提取}

相比制度下的格局演变、博亦下的空间利用, 以及 建筑内部经济价值最大化的平面形制。城中村建筑的立 面与细部是最丰富的层面——自发建造下民间意志与审 美偏好的表达。

\subsection{1. 入口}

在中山东路、中山南路的主要商业街, 出于城市综 合整治工作的风貌整改, 呈现出D1的形式。居住建筑, 多为直接入户式D2, 少数为有庭院的门院式D3。有丰富 的入口营造样式:带有仿古屋檐的大门、青砖墙体, 或白 色、红色马赛克贴面的坡道与台阶, 也有混凝土片墙分 割内外空间，在统一中富有变化（图8）。

每户内部的平面格局, 根据厅堂、是否独立厨卫, 及其相互之间的位置关系，总结为4种户型（图7）。

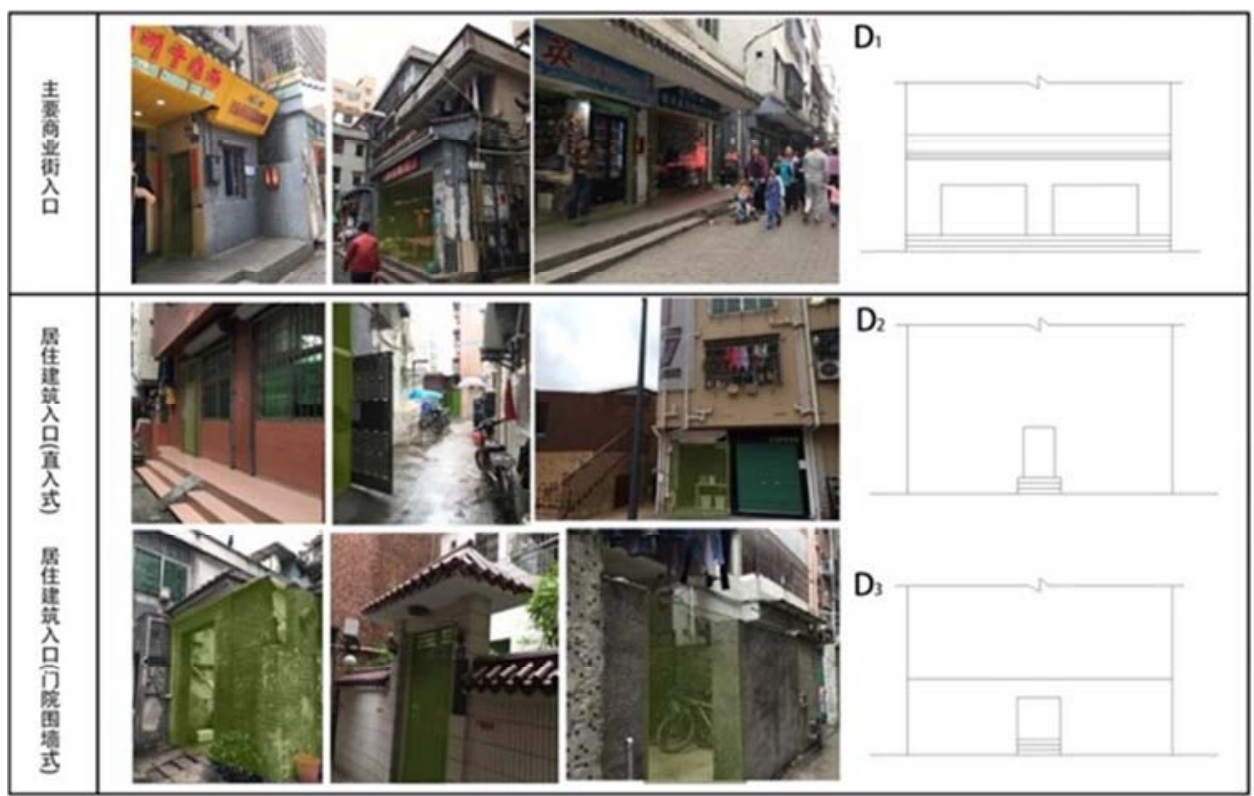

图8 入口方式类型提取。

\subsection{2. 窗洞}

立面是村民可以充分自由发挥的层面。窗洞形式多样, 存在错层布置。因使用砖砌结构, 长条窗较少, 多为独立 窗洞, 喜用有色玻璃。形态多样 (图9)。 


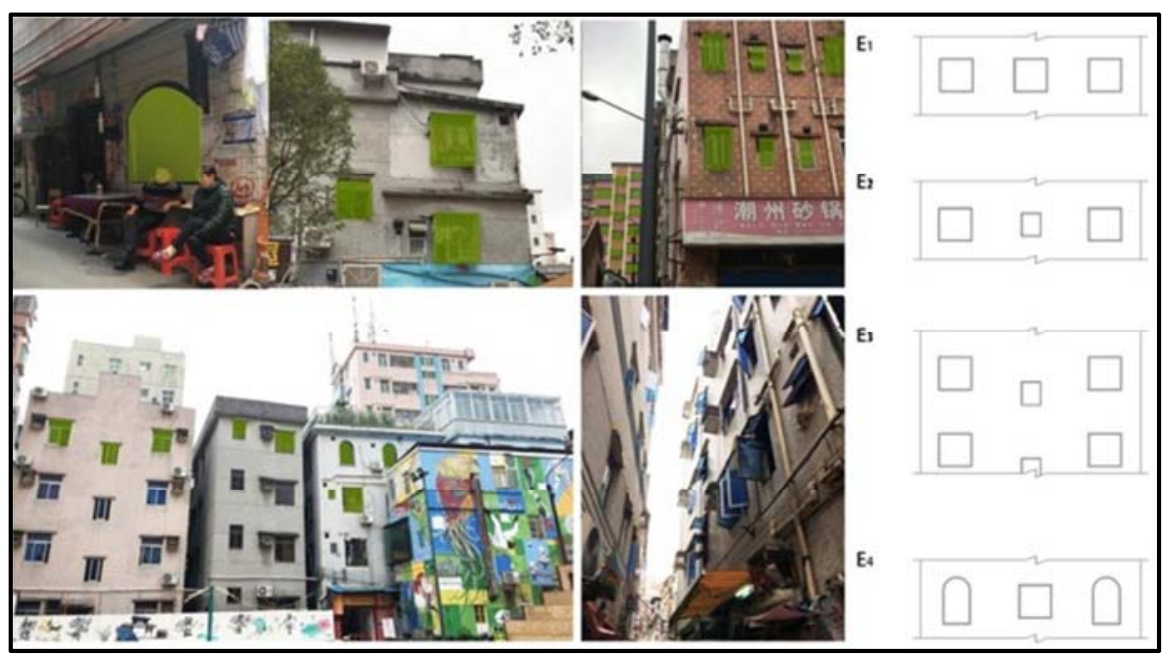

图9 窗洞类型提取。

\subsection{3. 阳台}

深圳湿热的气候下, 开敞阳台普遍存在, 而南头古城 中并不多见。楼间距太近，视线干扰、安全问题以及污水、 雨水飞溅等原因, 使城内多数建筑阳台为封闭式。在中山 东路两侧的开敞阳台数量明显多于居住区内部, 由此可见, 阳台开敞与否与阳台所处空间的开放程度相关。周边的阳
台开敞程度也会影响居民的决策，若周边都是封闭阳台， 居民也倾向于将自家阳台封闭起来，是多种原因共同作用 下的结果。出于对公共空间的竞争，存在大量出挑且封闭 的阳台（F32），出于城中村多样性的特征。按照是否出 挑、所在街道、是否封闭分为6中类型（图10）

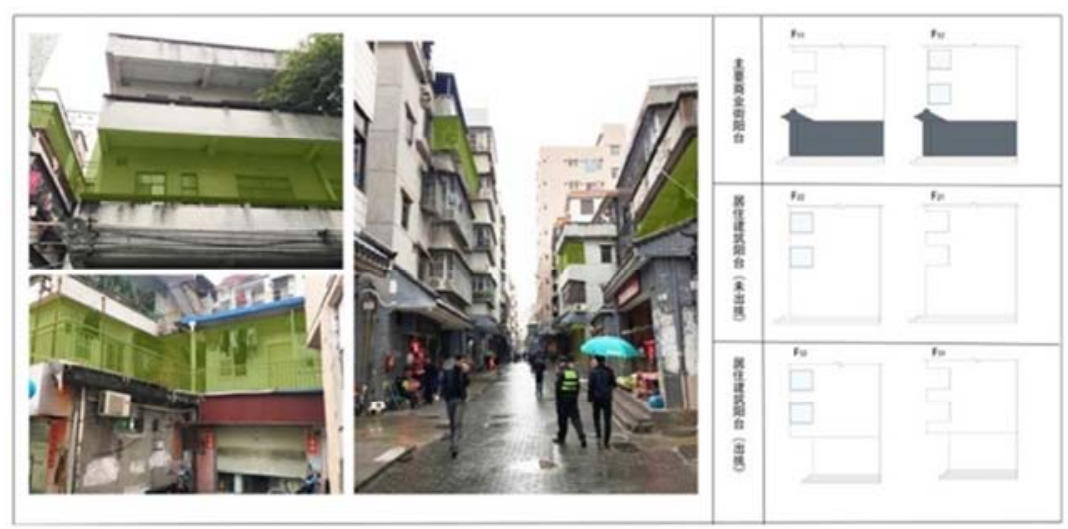

图10 阳台类型提取。

\subsection{4. 材质}

随机选取乐平街进行材质收集分析 (图11)。相比 其他地区, 南头古城中瓷砖贴面的使用率明显偏高。湿 热多雨的气候下, 高密度的房屋空隙中, 阳光稀缺, 幽
暗潮湿, 防水、防潮问题凸显。瓷砖光滑、防水、易于 清理。此外。瓷砖具有一定的反光度, 反射光可以改善 街巷中的采光。

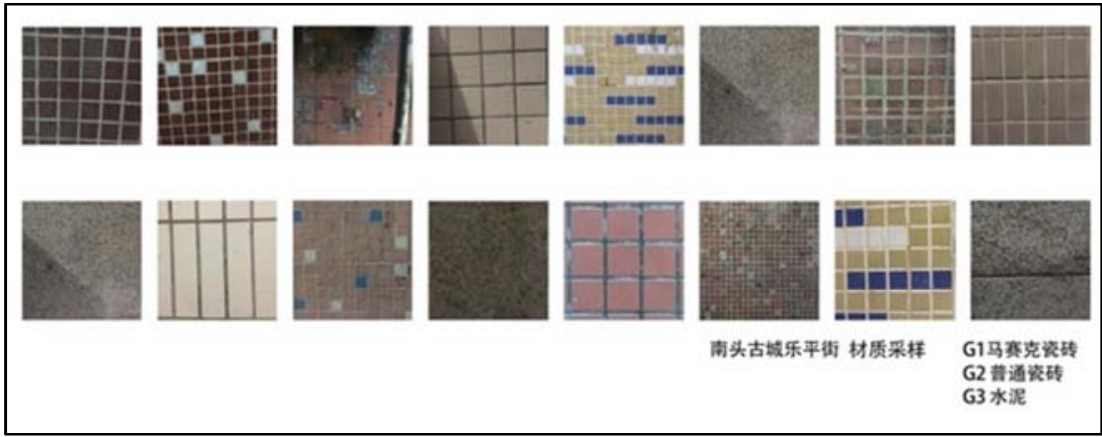

图11 材质类型提取。 


\subsection{5. 色彩}

城中村多样的色彩是居民自发建造家园中审美意趣 的风俗表现。村民在建造中, 考虑自身喜好, 以及与周
围环境的关系。无意中形成包容度高而丰富的色彩变化。 灰白色调之外常点缀红色系、黄色系 (图12)。

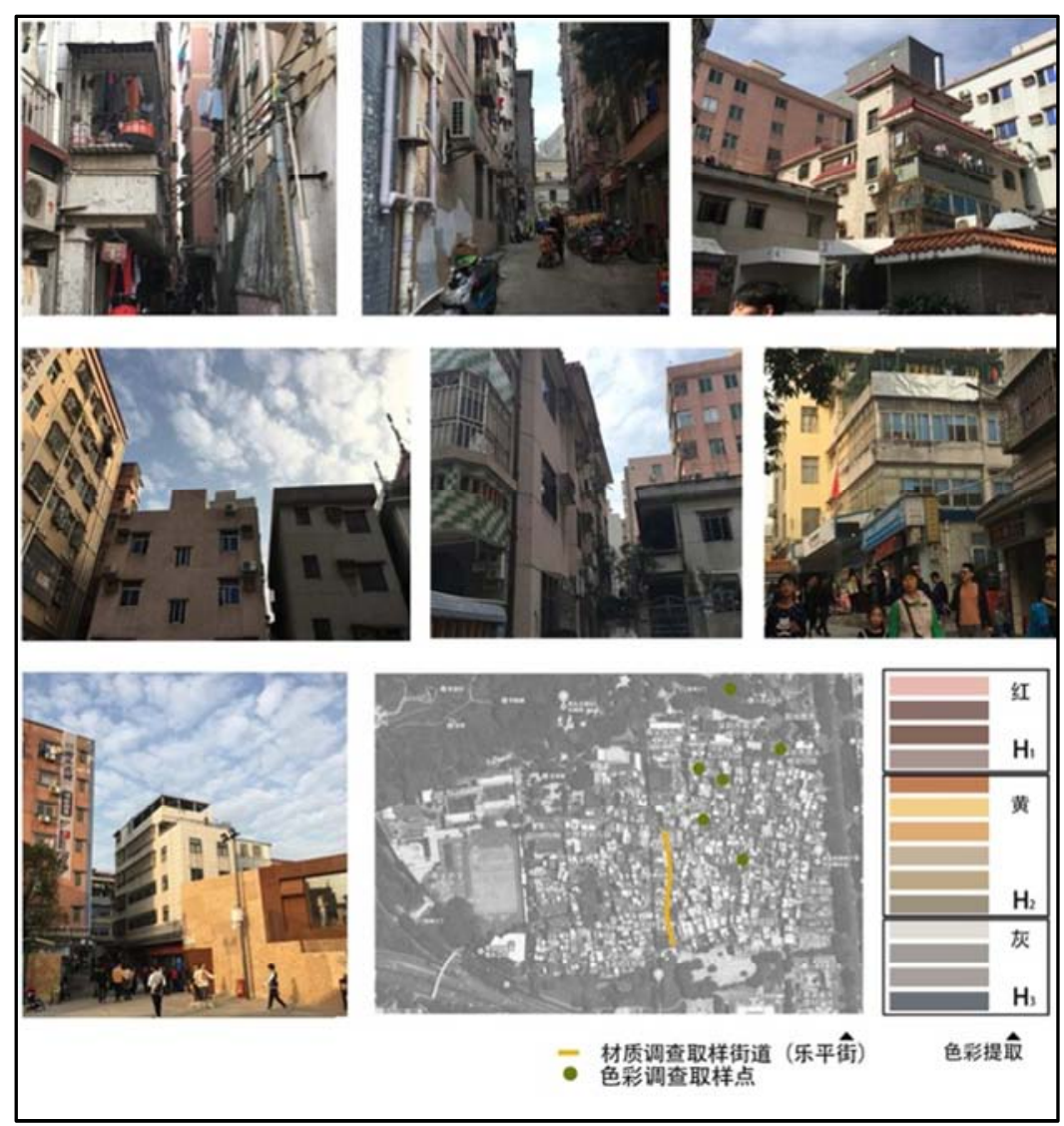

图12 色彩提取。

\subsection{6. 屋顶形式}

由于村民对法制规定的认识的欠缺及滞后性，村民 容易出现跟风加建行为。五层半可以扩充到六层甚至更
高, 常采用临时搭建的形式, 将半层扩充到一层。使平 屋顶，半层屋顶，临时加建造的屋顶三种形式并存（图 13)。

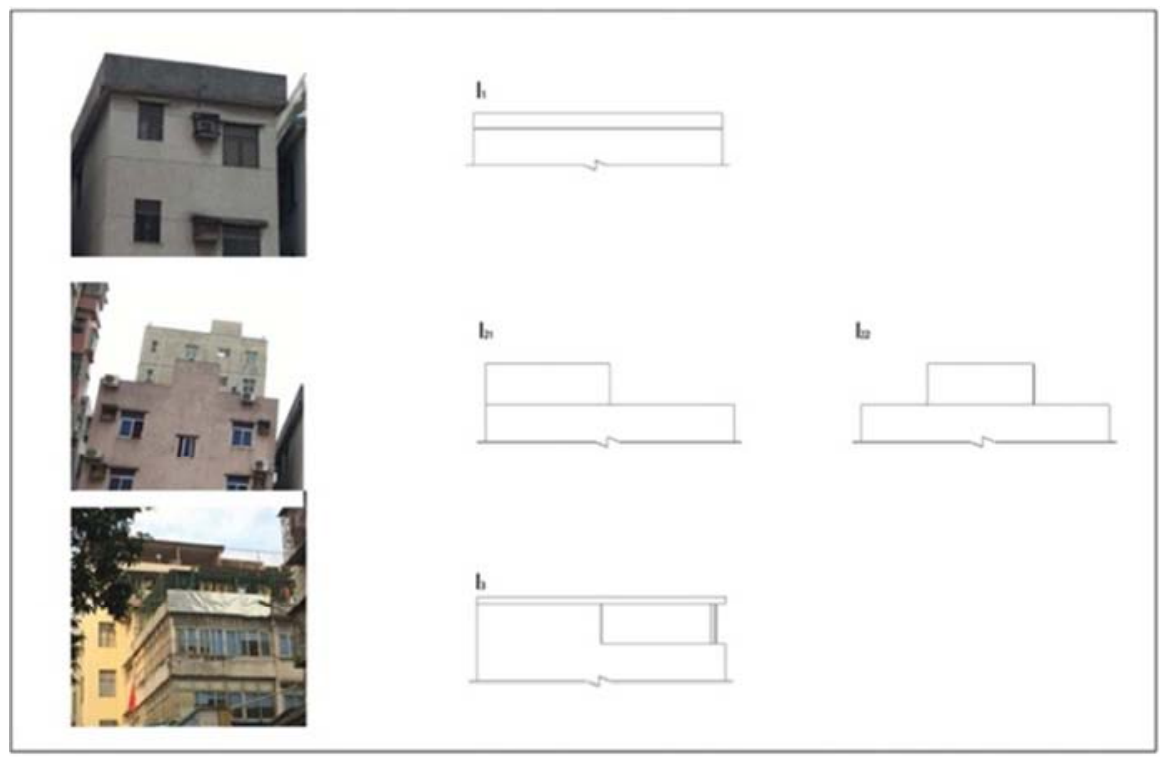

图13 屋顶形式提取。 


\subsection{7. 类型组合}

类型的提取有利于更清晰地对城中村已有形态进行 分类和梳理, 利用提取的原型进行组合可生成丰富的典 型城中村自建建筑形态（图14）。
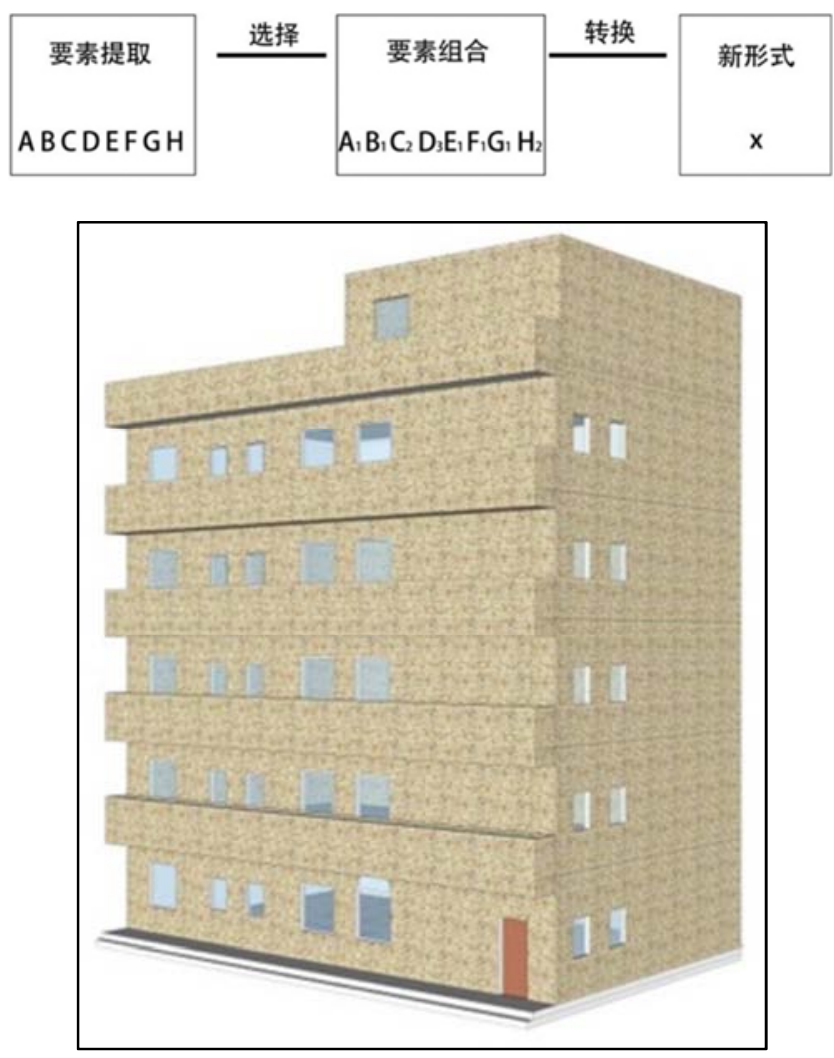

图14 建筑类型组合。

\section{4. 结语}

城中村特有的自组织建造方式, 蕴含着特定文化与 具体场所的契合, 以及空间对建造者意图精微的适应性, 是主体的自然选择。[9]以自发建造为切入点梳理其形态 特征, 便于理解其特有形式下呈现出来的共性与多样性, 以及历时性变化引发的复杂性, 为重新审视其复杂形态 下的社会内涵提供借鉴。
当下城中村面临的微更新模式, 是更精微的干预过 程, 城中村复杂的社会生态不同于其他社区, 需要从各 方面深入理解和把握, 鼓励多元参与下的社区营造, [10] 重视并引导居民发挥其主观能动性, 在尊重其特有原生 风貌的情况下进行保留、取舍与改造。

\section{参考文献}

[1] 吴粀.自组织方法论研究 [M]. 北京: 清华大学出版社, 2001:10-34。

[2] 林雄斌, 马学广, 李贵才. 快速城市化下城中村非正规性的 形成机制与治理 [J]. 经济地理, 2014, 34(6):162-168。

[3] 祝莹. 历史街区保护中的类型学方法研究[J]. 城市规划学刊, 2002(6):57-60。

[4] 刘簽. 利益博弯: 解决“城中村”问题的思路探讨——以深 圳市为例 [J]. 重庆行政: 公共论坛, 2006(4):70-72。

[5] 姚圣, 唐怡. 英国Conzen城市形态学派理论研究初探[C].城 市规划和科学发展—-2009中国城市规划年会论文集. 2009。

[6] 佚名. 城市历史之根一一南头古城[J]. 经济前沿, 2005(12): 88-89。

[7] 全德, 冯长春, 邓金杰. 城中村空间形态的演化特征及原因 ——深圳特区为例 [J].地理研究, 2011, 30(3):437-446。

[8] 许志强, 广州大学建筑与城规学院教师. 城中村自建房研 究——建造与博弯 [DB/OL].https://www.thepaper.cn/newsDetail_forward_1651434, 2017-03-31.

[9] 卢健松. 自发性建造视野下建筑的地域性[J]. 建筑学报, 2009(s2): 3-7。

[10] 郭臻. 转型期我国社会多元利益冲突与政府的角色定位一 一以广州、珠海市城中村改造的实践为例 [J]. 学术研究, 2008(6): 69-73。 